\title{
Minimal Invasive Approach in Atrophic Jaws Rehabilitation Using A Reduced Number of Implants
}

\author{
Angelo Cardarelli ${ }^{1 *}$, Michele Grechi ${ }^{1}$, Leonino Lago ${ }^{1}$, Federico Quasso ${ }^{1}$ and Enrico Felice Gherlone ${ }^{2}$ \\ ${ }^{1}$ Department of Dentistry, University “Vita-Salute” San Raffaele Milano, Italy \\ ${ }^{2}$ Full Professor and Dean Department of Dentistry, IRCCS San Raffaele Hospital, Milan, Italy
}

*Corresponding author: Angelo Cardarelli, Adjunct Professor Department of Dentistry Ircss San Raffale Hospital Milan, Italy.
Received Date: June 28, 2019

Published Date: August 01, 2019

\section{Abstract}

In partially or totally edentulous patient, the jaws can have severe limitation for conventional implant treatment. Resorption of jaw reduce in many cases the amount of bone available both in thickness and height, and in the lower jawbone quality is less dense, more bone narrow and thinner than the forehead. The purpose of this work is to present an alternative technique to normal sinus lift in the upper jaw and bone graft in the mandible with minimal invasive approach to reduce biological costs, without bone regeneration with immediate loading, immediate aesthetic and immediate function.

\section{Introduction}

Implant-prosthetic rehabilitations of immediate jaws represent a therapeutic possibility with a high success rate and satisfaction for the surgeon and the patient. However, the anatomy of the jaws, periodontal and iatrogenic problems represent limitations to the conventional rehabilitations of edentulous patients and with serious problems of the residual dental elements that would necessary preimplant bone regeneration treatments. These methods are to be considered for patients with a high biological and economic cost, with high morbility and based on the operator experience. For these reasons, the modern implant guidelines are based on clinical protocols that used the residual basal bone without bone regeneration. These methods, well supported by scientific data, provide for an immediate restoration of the function by positioning implants with immediate loading [1-4]. This approach is based on the placement "straight" implants in anterior area and tilted in posterior area. The reduced number of implant rehabilitations, whether they are inclined or not, are proved by numerous scientific studies showing that four implants are sufficient to support a fullarch prosthesis. Since the immediate loading of tilted and axial implants with placement of an immediate provisional prosthesis is proposed as a predictable, fast and cheap method to treat jaws atrophy, the purpose of this article is to illustrate the atrophic jaws rehabilitation with immediate loading of a patients with severe problems of residual dental elements using only basal bone [5-14].

\section{Materials and Methods}

Case 1
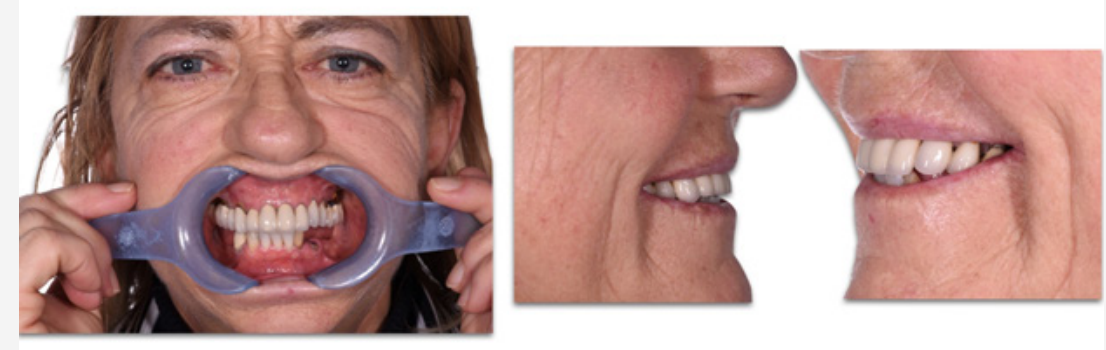

Figure 1: Initial situation Extra-Oral. 
In the first case it is described a woman patient of 65 years, in good health, with a negative history, smoker. The clinical and radiographic examination shows a serious periodontal disease, with morbility of the residual dental elements. So, we decided to remove dental elements residues, and to insert 5 implants with immediate loading. (Figure 1-3)
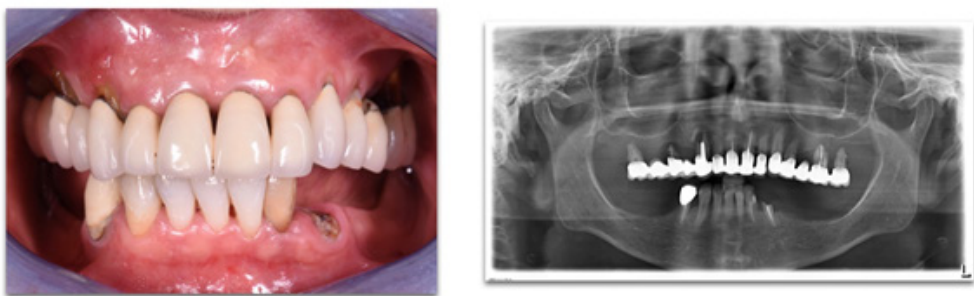

Figure 2: Intra Oral situation and OPT.

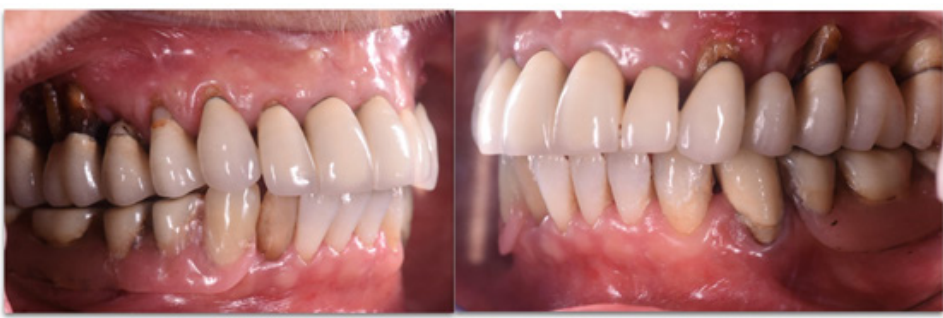

Figure 3: Right and left Intra Oral site.
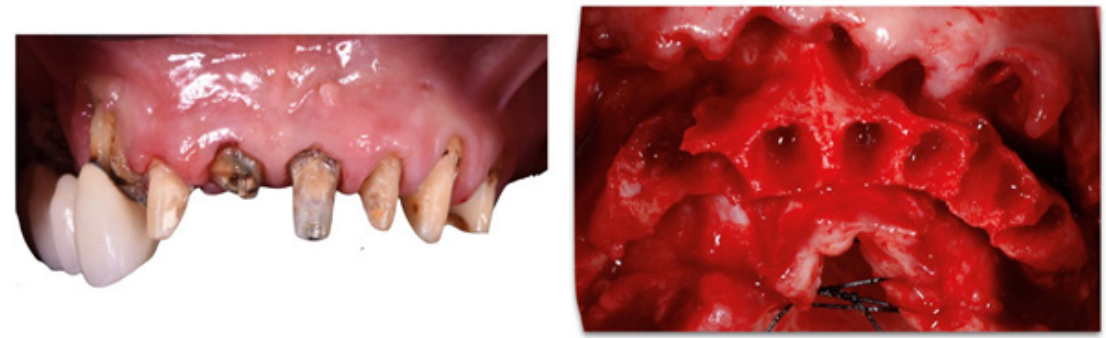

Figure 4: Sugical phase remove dental elements.
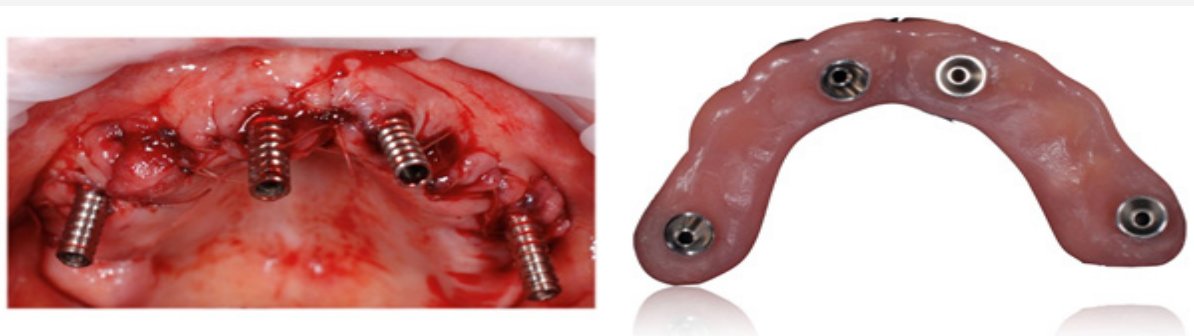

Figure 5: Immediate loading.
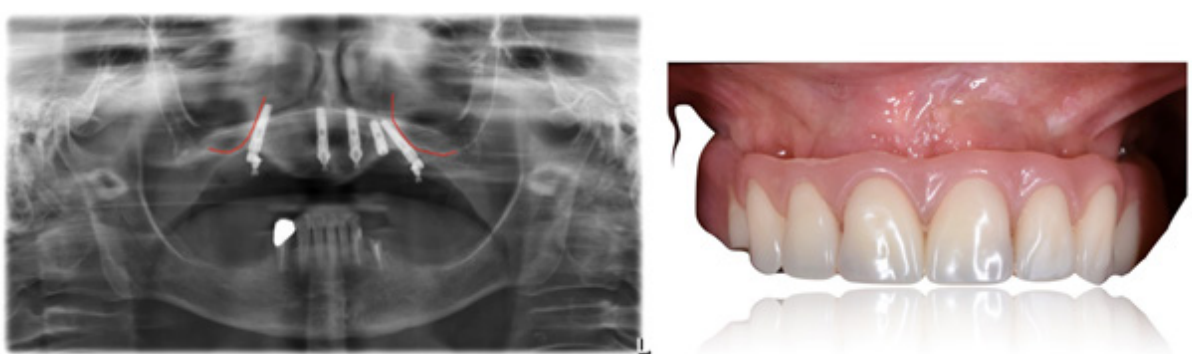

Figure 6: RX post surgeryand Temporary rehabilitation. 

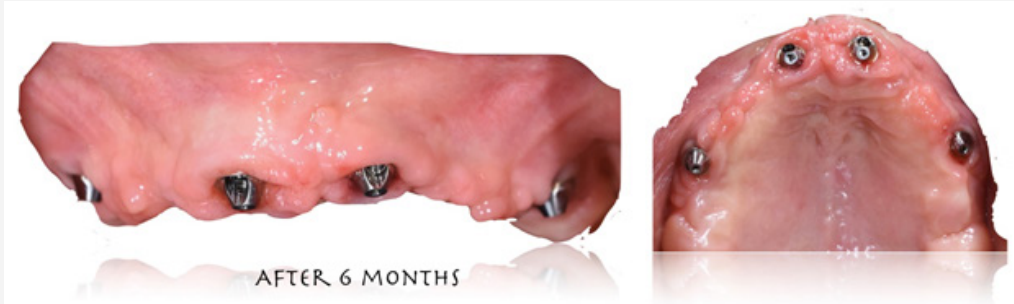

Figure 7: Healing hard and soft tissue after 6 months.

\section{Surgical and prosthetic procedures}

One hour before the operation, $1 \mathrm{~g}$ of amoxicillin is given to the patient, to be taken twice a day for the following 6 days. Surgical procedures are started under local anesthesia, $20 \mathrm{mg} /$ $\mathrm{mL}$ optocaine with 1: 80,000 adrenaline. So dental elements are removed, then a crestal incision is made from the area of the first right molar to the first left molar with two distal mucoperiosteal incisions to research the anterior wall of maxillary sinus. The distal osteotomy has tangential to the anterior wall of the maxillary sinus: this inclination makes it possible to obtain an emergence of the implant platform at the level of the first molar The posterior implants, with a diameter of $4.0 \mathrm{~mm}$ and a length of $15 \mathrm{~mm}$ (OSSTEM), are positioned. The posterior implants generally emerge in the position of the second premolar. Subsequently, three axial implants are positioned, two $4.0 \mathrm{~mm}$ in diameter and $15 \mathrm{~mm}$ in length (OSSTEM) and one 4.0 diameter and 13 length. For the anterior implants are positioned Extreme Abutments of 17 degrees, while for the posterior of 30 degrees to obtain a parallelism between the fixtures. These degrees of angulation are chosen to allow the access hole of the prosthetic screw an occlusal or lingual position with respect to the teeth mounted on the provisional prosthesis. The suture is made with $4 / 0$ silk thread. At the end of the surgery the previously made temporary prosthesis is screwed According to the diagnostic set up, whose vertical dimension is established. One of straight implants has not been done immediate loading because it hasn't a sufficient primary stability FOTO 4-5-6-7. The patient is given a semisolid diet for 2 months following the operation. At 6 months from the osseointegration and stabilization of the soft tissues the impressions are detected and placed a screwed toronto with material PEEK with weight only 18 grams. (Figure 8-13)
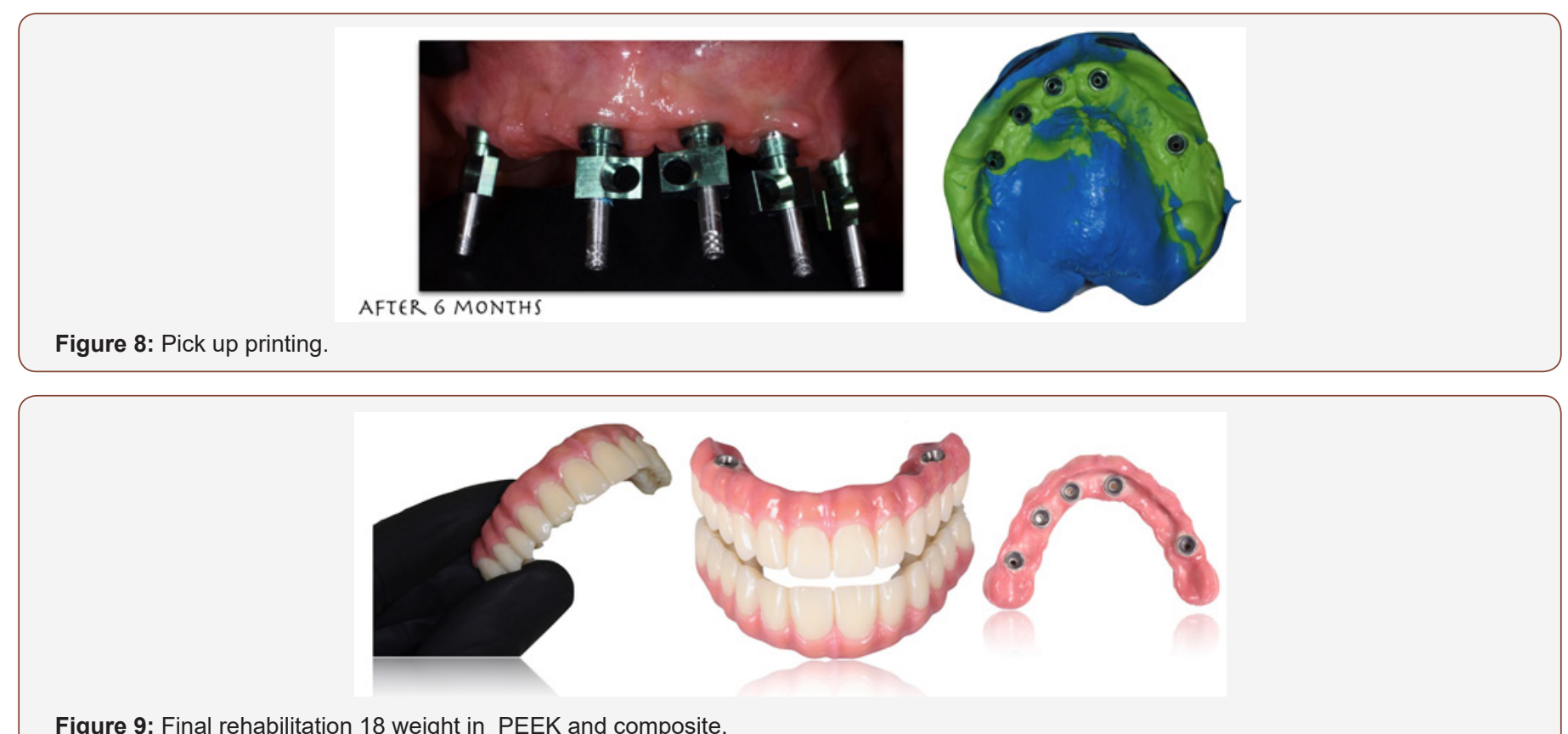

Figure 9: Final rehabilitation 18 weight in PEEK and composite.
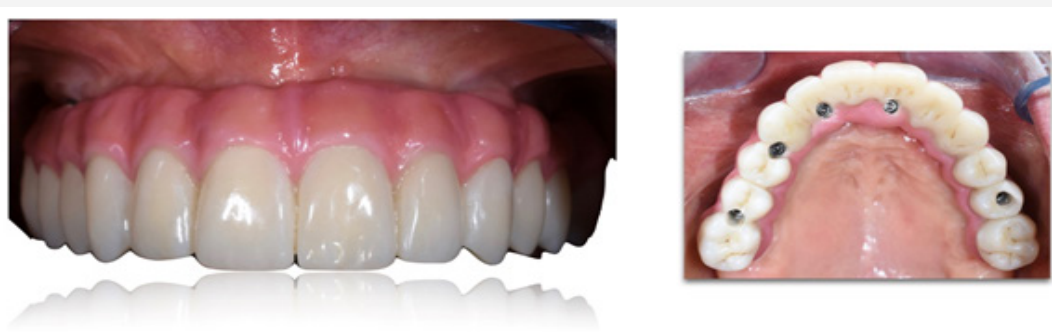

Figure 10: Final aesthetic result. 

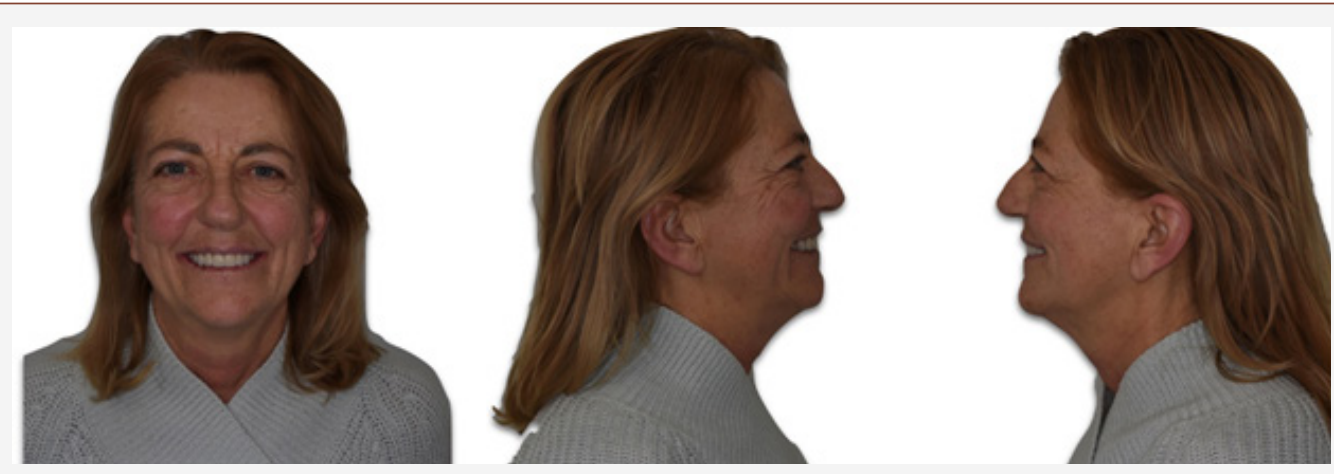

Figure 11: Final rehabilitation.

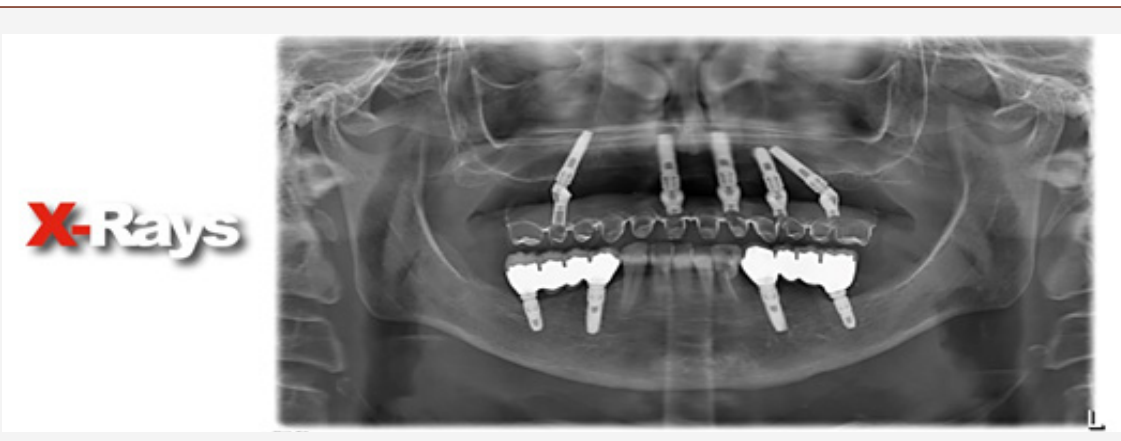

Figure 12: Followup 24 months.

\section{Case 2}

In this case it is described a woman patient of 69 years, in good health, with a negative history, not a smoker. The clinical and radiographic examination (OPT and Cone Beam) shows a serious periodontal disease, with morbility of the remaining dental elements with severe atrophy. So, the planning will be to remove dental elements residues, and to place 4 implants with immediate loading according to the "All on 4" method. (Figure 1-3). One hour before the operation, $1 \mathrm{~g}$ of amoxicillin is given to the patient, to be taken twice a day for the following 6 days. Surgical procedures are started under local anesthesia, $20 \mathrm{mg} / \mathrm{mL}$ optocaine with 1 : 80,000 adrenaline. So dental elements are extracted, then a crestal incision is made from the middle of mandible to the posterior area to preserve alveolar nerve without mucoperiosteal incisions to research the emergence of alveolar nerve. The posterior implants, with a diameter of $3.8 \mathrm{~mm}$ and a length of $13 \mathrm{~mm}$, are positioned above the mentally foramen and inclined mesially by 30-45 degrees to the occlusal plane. The axial implants are positioned $3.8 \mathrm{~mm}$ in diameter and $11 \mathrm{~mm}$ in length (Winsix Biosafin) For the front implants are positioned Extreme Abutments straight, while for the posterior of 30 degrees to compensate for the lack of parallelism between the fixtures. These degrees of angulation are chosen to allow the access hole of the prosthetic screw an occlusal or lingual position with respect to the teeth mounted on the provisional prosthesis. The suture is made with $4 / 0$ silk thread. At the end of the operation the previously made temporary prosthesis is screwed according to the diagnostic set up, whose vertical dimension is established and corrected by the study of master model and the cephalometric study. The patient is given a semisolid diet for 2 months following the operation. At 4 months from the osseointegration and stabilization of the soft tissues the impressions are detected and placed a screwed toronto with composite material. (Figure 4-8)
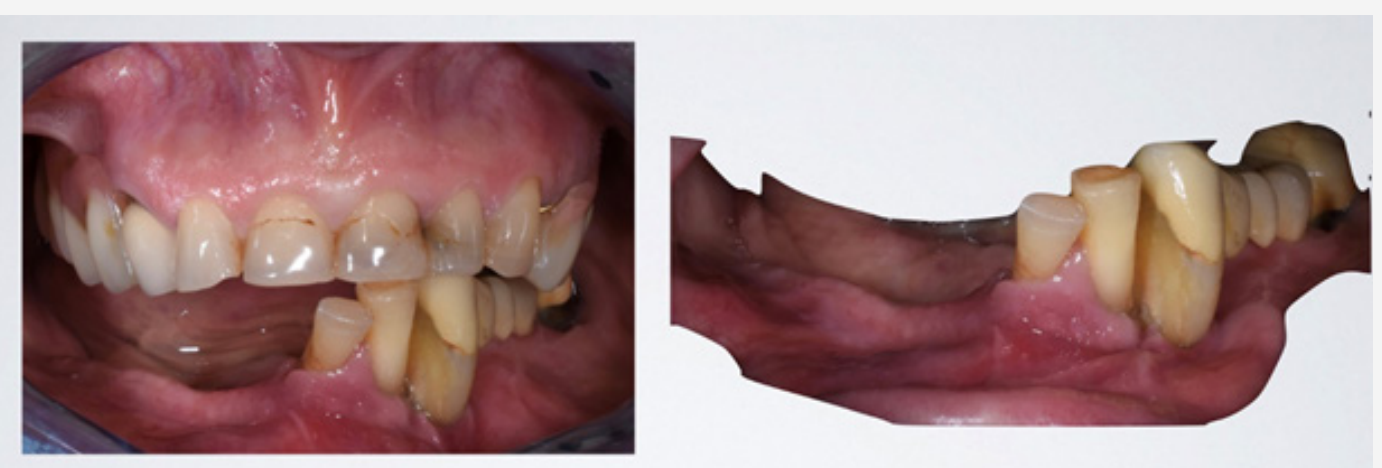

Figure 1: Initial situation. 

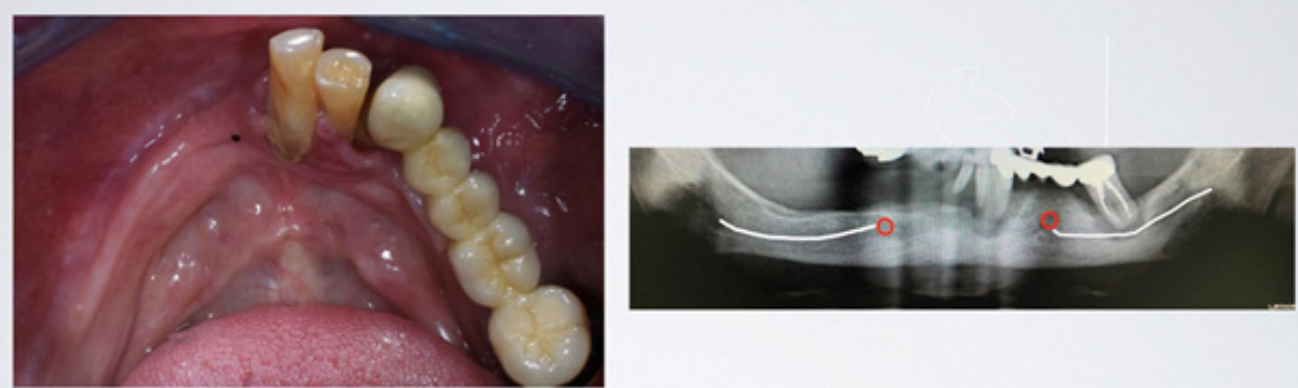

Figure 2: Intra Oral situation and RXOPT.
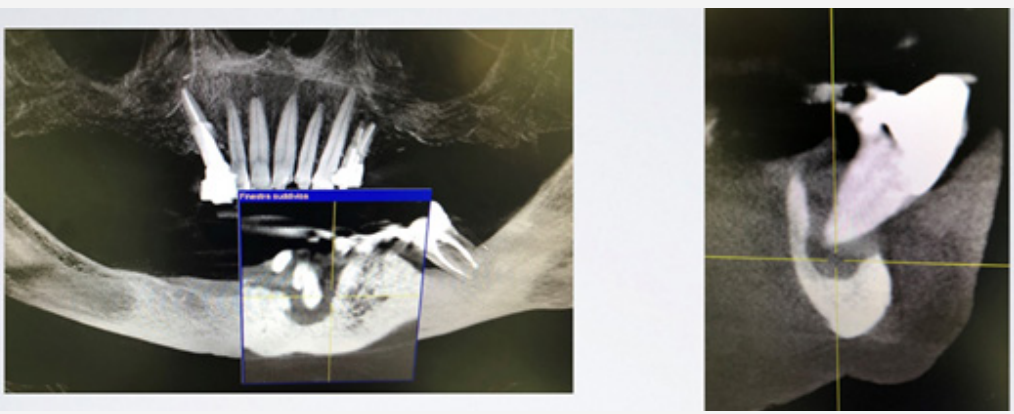

Figure 3: Tac cone beam.
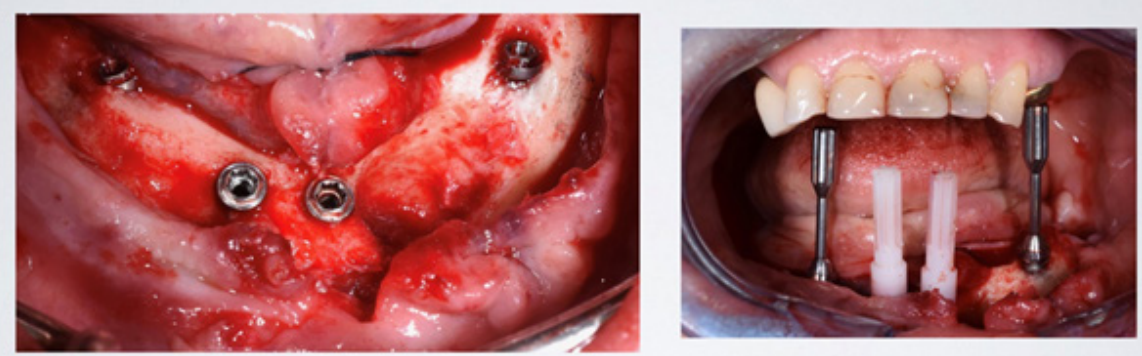

Figure 4: Implant placement after extractions.

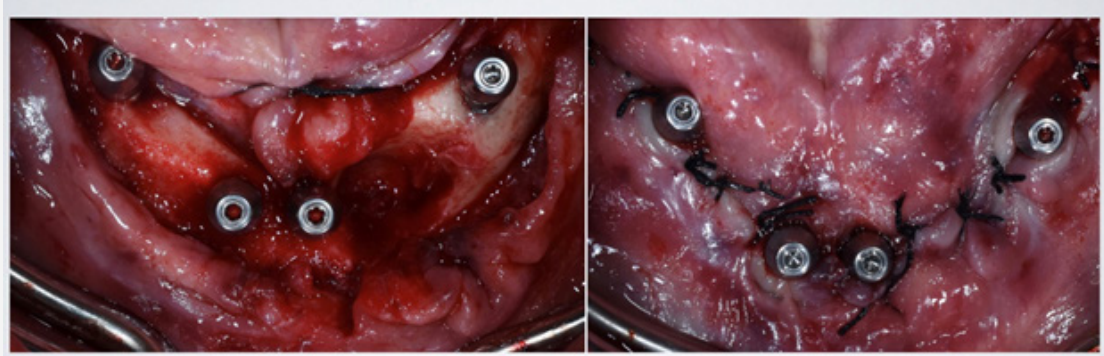

Figure 5: Suture.
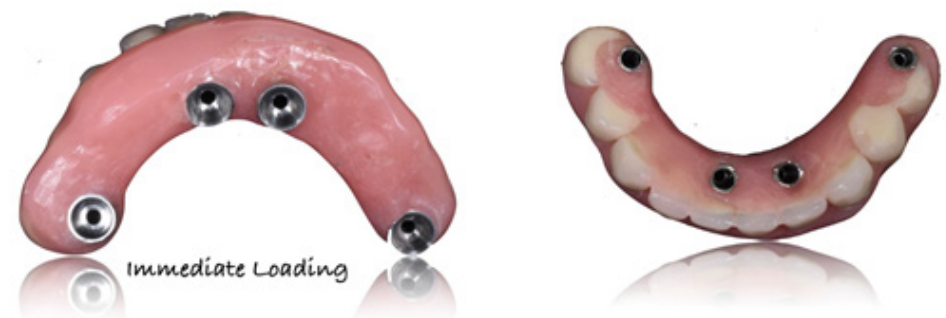

Figure 6: Temporary rehabilitation. 
Figure 7: Immediate loading.
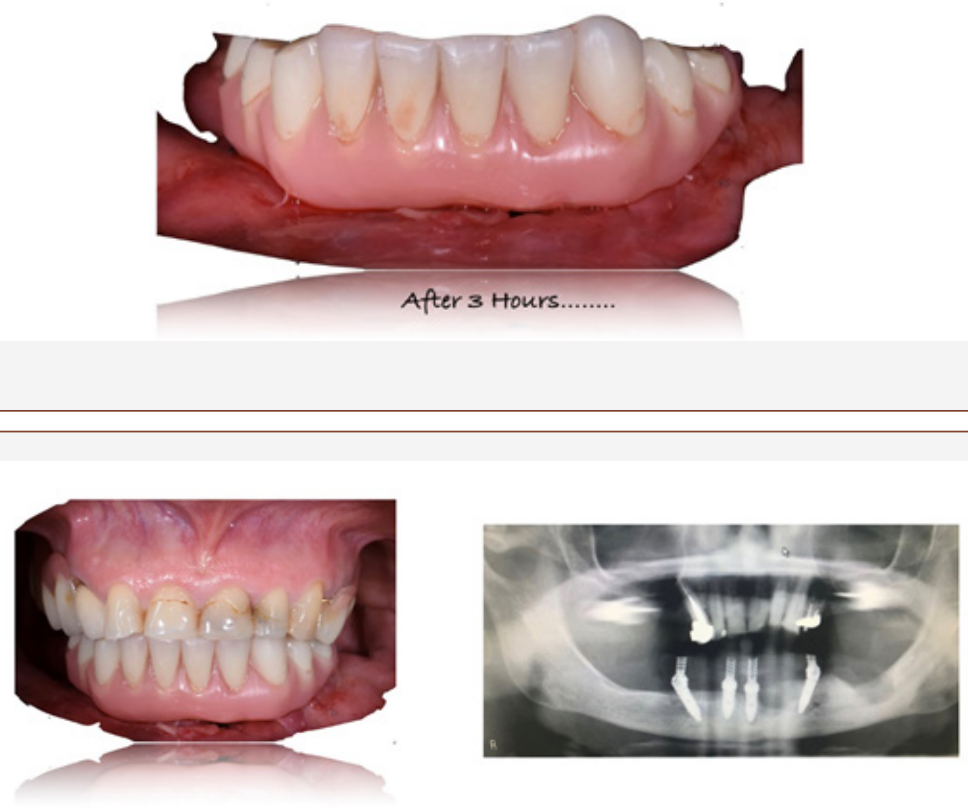

Figure 8: Final RX and All-On-4 Rehabilitation.

\section{Results and Conclusion}

At the 24-month follow-up the clinical and radiological appearance of soft and hard tissues is optimal and no pathological signs or prosthetic complications were recorded. This surgical technique represents a valid and predictable therapeutic alternative to the techniques of bone augmentation and regeneration. The biomechanical aspect on which the use of angled implants is based is the reduction of the cantilever and therefore a better and homogeneous distribution of the loads at the prosthetic level. Numerous studies have reported a high survival rate, others have assessed the amount of stress in the peri-implant bone, these studies showed that the single angled implant. Subjected to axial loads presents greater perimplant bone stress than the single axial implant; however, when the angled implants is joined to other implants with an educed cantilever, it presents a minor mechanical stress at the per implant level compared to solidarizza implants but with a greater cantilever.

\section{Acknowledgements}

None.

\section{Conflict of Interest}

No conflict of interest.

\section{References}

1. Chiapasco M (2004) Early and immediate restoration and loading of implants in completely edentulous patients. Int J Oral Maxillofac Implants 19(suppl): 76-91.

2. Del Fabbro M, Testori T, Francetti L, Taschieri S, Weinstein R (2006) System- atic review of survival rates for immediately loaded dental implants. Int J Peri odontics Restorative Dent 26(3): 249-263.

3. Malo P, Rangert B, Nobre M (2003) All-on-Four immediate function concept with Brånemark system implants for completely edentulous mandibles: A retrospective clinical study. Clin Implant Dent Res 5(suppl 1): 2-9.

4. Malo P, Rangert B, Nobre M (2005) All-on-4 immediate function concept with Brånemark system implants for completely edentulous maxil- lae: A 1-year retrospective clinical study. Clin Implant Dent Relat Res 7(suppl 1): S88-S94.

5. Duyck J, Van Oosterwyck H, Vander Sloten J, De Cooman M, Puers R, et al. (2000) Magnitude and distribution of occlusal forces on oral implants supporting fixed prostheses: An in vivo study. Clin Oral Implants Res 11(5): 465- 475 .

6. Aparicio C, Perales P, Rangert B (2001) Tilted implants as an alternative to maxillary sinus grafting. Clin Implant Dent Relat Res 3(1): 39- 49.

7. Krekmanov L, Kahn M, Rangert B, Lindstrom H (2000) Tilt ing of posterior mandibular and maxillary implants of improbe prosthesis support. Int J Oral Maxillofac Implants 15(3): 405- 414.

8. Maló P, Nobre Mde A, Petersson U, Wigren S (2006) A pilot study of complete edentulous rehabilitation with immediate function using a new implant design: Case series. Clin Implant Dent Relat Res 8(4): 223-232.

9. Stegaroiu R, Khraisat A, Nomura S, Miyakawa O (2004) Influence of super-structure materials on strain around an implant under 2 loading conditions: A technical investigation. Int J Oral Maxillofac Implants 19(5): 735-742.

10. Tealdo T, Bevilacqua M, Pera F, Menini M, Ravera G, et al. (2008) Immediate function with fixed implant-supported maxillary dentures: A 12-month pilot study. J Prosthet Dent 99(5): 351-360.

11. Grunder U (2001) Immediate functional loading of immediate implants in edentulous arches: Two- year results. Int J Periodontics Restorative Dent 21(6): 545-551.

12. Skalak R (1983) Biomechanical considerations in osseointegrated prosthe- ses. J Prosthet Dent 49(6): 843- 848.

13. Juodzbalys G, Kubilius R, Eidukynas V, Raustia AM (2005) Stress distribution in bone: Sin gle-unit implant prostheses veneered with porce- lain or a new composite material. Implant Dent 14(2): 166-175.

14. Crespi R, Vinci R, Capparé P, Romanos G. E, Gherlone E (2012) A Clinical Study of Edentulous Patients Rehabilitated According to the "All on Four". Int J Oral Maxillofac Implants 27(2): 428-434. 